\title{
CONCEPÇÕES DE LÍNGUA(GEM) E LEITURA: PRÁTICAS DE PROFESSORES DE LÍNGUA INGLESA EM ATUAÇÃO
}

\section{Language and reading conceptions: English teaching practices in action}

\author{
Clarita Gonçalves de CAMARGO, SPEI ${ }^{1}$ \\ Isabel Cristina Vollet MARSON, $\mathrm{UEPG}^{2}$ \\ Rosana Hass KONDO, SEED-PR ${ }^{3}$
}

\begin{abstract}
RESUMO: Partindo do pressuposto que a maneira como o professor entende e reflete sobre língua(gem) interfere diretamente na sua ação pedagógica em sala de aula, pretende-se neste artigo discutir a respeito das concepções de língua(gem) e de práticas de leituras que professores de língua inglesa possuem, e como essas perspectivas intervém nas suas ações pedagógicas. A pesquisa foi realizada com seis professores de língua inglesa pertencentes a três localidades do Paraná: Ponta Grossa, Curitiba e Tomazina. Os dados foram gerados a partir de questionários estruturados e semiestruturados e, posteriormente foram analisados qualitativamente. Os resultados levaram a conclusão de que, apesar dos professores se mostrarem abertos a concepções pós-estruturalistas, e também acreditarem na língua(gem) como ideológica, permeada por relações de poder, as suas práticas ainda refletem um ensino estruturalista, o qual pode ser verificado pela recorrência do termo norma-padrão e ao controle do professor em sala de aula, em manipular mais a forma linguística do que o seu significado em contexto comunicativo.
\end{abstract}

PALAVRAS - CHAVE: Concepção de língua(gem); Prática de Leitura; Língua Inglesa, Formação de professores.

ABSTRACT: The way the teacher understands and reflects on language interferes directly in his/her pedagogical practice in the classroom. In this article we reflect and argue about the language and reading conceptions that English teachers have, and how these perspectives intervene in their pedagogical practices. The research was carried out with six English teachers from three cities of Paraná: Ponta Grossa, Curitiba and Tomazina. The data was generated by structured and semi-structured questionnaires which were analyzed qualitatively afterwards. The results showed that despite teachers being opened to poststructuralist conceptions and their belief in language as ideological, permeated by power relations, their practices still reflect a structuralist teaching, which can be verified by the recurrence of English standard term and the teacher control in the classroom in manipulating the linguistic form instead of its meaning in communicative context.

KEYWORDS: Language conception; Reading practice, English Language, Teacher development.

\footnotetext{
${ }^{1}$ Doutoranda em Letras (UFPR) e docente do Grupo de ensino Rosário e Faculdade SPEI. clarita_camargo@yahoo.com.br

${ }^{2}$ Doutoranda em Letras (UFPR) e docente da Universidade Estadual de Ponta Grossa. isabel.marson@yahoo.com.br

${ }^{3}$ Doutoranda em Letras (UFPR) e docente da SEED-PR. rosanahass@gmail.com
} 


\section{INTRODUÇÃO}

Considerando que somos sujeitos construídos socialmente e historicamente, através de nossos discursos na interação diária com o outro, podemos dizer que a enunciação que se reproduz no diálogo entre os interlocutores “[...] é de natureza social, portanto ideológica. Ela não existe fora de um contexto social” (BAKHTIN, 2006, p.17). Dessa forma, podemos dizer que o modo como o docente trabalha questões relacionadas a língua(gem $)^{4}$ está intrinsecamente relacionada com a sua formação. Nesta direção, partindo do entendimento de que a maneira como o docente concebe língua(gem) pode interferir diretamente no modo como este ensina, pretendemos neste artigo discutir e refletir sobre as concepções que têm embasado as práticas de alguns professores de língua inglesa das cidades de Curitiba, Ponta Grossa e Tomazina, no Estado do Paraná. Acreditamos que esta pesquisa possa servir para refletirmos como tem sido as práticas desses professores atuantes nas escolas.

Desse modo, primeiramente trazemos uma discussão teórica sobre as principais concepções de língua(gem), e suas possíveis influências na percepção prática desses professores de Língua Estrangeira (LE)/Segunda Língua (L2). Dentre as concepções que norteiam o ensino-aprendizagem de língua estrangeira, decidimos limitar a pesquisa a três concepções: língua como expressão do pensamento, língua como instrumento de comunicação e língua como forma de interação (GERALDI, 1984 apud BORGES, 2016). A escolha não se deu por se tratar de concepções antagônicas ou excludentes mas, sim, porque são concepções que norteiam o ensino de línguas no Brasil. Nesta direção, escolhemos trechos de concepções de língua de alguns autores (sem explicitar a autoria da citação no questionário) para que os professores verificassem se havia congruências ou desacordos com suas práticas pedagógicas. Assim, após escolherem a concepção mais condizente do que seria ensinar/aprender língua(gem), solicitamos ainda que respondessem, por meio de uma pergunta $a^{2} e^{5}{ }^{5}$, qual concepção guiava sua prática.

\footnotetext{
${ }^{4}$ Utilizamos o termo língua(gem) por considerarmos que os dois fenômenos são distintos (língua e linguagem), mas ao mesmo tempo intercambiáveis. Na visão de Bronckart (2006, p. 79) “[...] a linguagem se constitui, de início, como uma prática ilocutória da nacionalidade social que rege as ações humanas. Essa prática se solidifica em sistemas de signos, ou línguas naturais, que permitem uma (re)codificação locutória particular (sociocultural) das representações racionais do mundo". Ou seja, através da linguagem o sujeito se estabelece na sociedade e se reconfigura continuamente.

${ }^{5}$ A inserção da pergunta aberta se deu como uma oportunidade de complementar a ideia que o professor tem em relação a determinado tema, ou seja, se ele não concordasse plenamente com as citações apresentadas, ele poderia escrever sua própria concepção.
} 
Para fundamentar o estudo, discorremos sobre o termo letramento e os modelos de ensino que ultimamente têm sido objeto de muitas pesquisas no campo educacional. Em seguida, apresentamos o contexto da pesquisa e os preceitos metodológicos que orientou este trabalho, bem como a caracterização dos participantes. Posteriormente, por meio dos dados gerados e apresentamos a análise acerca da ideia do que vem a ser ensinar /aprender língua na perspectiva dos docentes entrevistados. Por último, elencamos nossas considerações finais.

\section{CONCEPÇÃO DE LÍNGUA(GEM)}

Nesta seção intencionamos fazer uma reflexão teórica das principais concepções de língua(gem) que embasam/embasaram o ensino de língua ao longo do tempo. Essa reflexão é importante, tendo em vista que esses pressupostos podem trazer implicações pedagógicas para o processo de ensino e aprendizagem. É importante estarmos conscientes de que nossas concepções marcam e lideram nossas ações no processo de ensinar e como isso se reflete na aprendizagem em sala de aula (LARSEN-FREEMAN, 2000).

Para alguns pesquisadores como Silva e Aragão (2013), Makoni e Pennycook (2007) é complexo conceituar língua(gem), talvez porque ela esteja tão impregnada nas nossas vidas que não podemos nos imaginar sem ela, “[...] a linguagem permeia todos os aspectos da experiência humana e cria, bem como reflete imagens dessa experiência"6 (KUMARAVADIVELU, 2006, p. 3). Com o objetivo de refletir sobre as concepções que guiam a prática dos professores de língua estrangeira, apresentaremos abaixo três breves visões de língua: língua como expressão do pensamento, língua como instrumento de comunicação e língua como forma de interação.

A língua como expressão do pensamento fundamenta-se na concepção da língua com um fim em si mesma, um produto finalizado e estável pautado na gramática normativa (POSSENTI, 1997). O tratamento da língua como sistema é direcionado pelo seu aspecto estrutural não considerando as influências do indivíduo com seu meio, nem manifestadas pelo seu uso. Saussure (2006), percursor desse pensamento, dizia que a língua é um objeto de natureza homogênea e tida como um sistema de signos linguísticos que não sofria condicionamento do meio social, e que era manipulada como se já

${ }^{6}[. .$.$] language permeates every aspect of human experience, and creates as well as reflects images of that$ experience". (tradução livre das autoras) 
houvesse um domínio cognitivo pré-determinado pela mente. Ou seja, língua, nesta perspectiva, não é tomada como construção social, que se molda aos falantes, aos seus objetivos e contexto, sendo, portanto, fluida, complexa e constantemente (re)construída. Pelo contrário, esta perspectiva concebe língua como sistema fixo e imutável, como algo que está dado e acabado. Desta maneira, para o autor, a língua é responsável em organizar o pensamento e promover sua expressividade, de forma sistemática e funcional. Saussure (2006, p. 22), defendia que a língua “[...] é a parte social da linguagem, exterior ao indivíduo, que, por si só, não pode nem criá-la nem modificá-la; ela não existe senão em virtude duma espécie de contrato estabelecido entre os membros da comunidade", ou seja, o sistema linguístico preexiste à sua relação social e deve possuir tratamento diferente a qual ele estabeleceu dicotomicamente entre langue e parole. Seus estudos também interferiram no contexto de ensino, trazendo um posicionamento estruturalista calcado na norma linguística enquanto parâmetro engessado para aprendizagem. Nesse cenário o ensino de língua LE/L2 sofreu influência do estruturalismo saussuriano por meio dos estudos do estruturalista norte-americano, Leonard Bloomfield (1926). Foi ele que priorizou maior precisão científica no estudo da linguagem "[...] e define o uso da linguagem mediante a concepção materialista (mecanicista e não dialética) e comportamentista (em termos de estímulo e reação), em que a língua pode ser analisada como um sistema, cujos elementos se organizam por certo comportamento geral" (BLOOMFIELD, 1926 apud DUARTE et al, 2013, p. 34), ou seja, o indivíduo podia responder a linguagem quando estimulado de forma mecanizada sob a influência de um modelo de falante.

Em outras palavras, a língua(gem) era aprendida quando repetida ou memorizada até que as estruturas fossem internalizadas. Esse processo também considerava a abordagem do ensino explícito gramatical, sem atribuir valor ao contexto comunicativo no qual perpassa a dinamicidade da linguagem. Com isso percebe-se que a língua é manipulada dentro de um sistema pronto e fechado em que a sua aquisição está na dependência das regras internas.

Por outro lado, a perspectiva da língua como instrumento de comunicação concebe a mesma como "[...] um conjunto de signos que se combinam segundo regras e que é capaz de transmitir uma mensagem, informações de um emissor a um receptor" (TRAVAGLIA, 1996, p. 22). Nesse modelo, o indivíduo se apropria do código para repassar a mensagem. 
A terceira concepção de língua como interação surgiu a partir dos princípios do Círculo de Bakhtin (BAKHTIN; VOLOCHINOV, 1992) em que a língua se constitui na relação com o outro. A linguagem numa posição interacionista tem em vista a aproximação dos indivíduos e suas relações pragmáticas na construção do significado, com uma abordagem em que a língua não é colocada como um sistema engessado, mas está em constante movimento e na dependência de seus usuários. Assim, na linguística aplicada, aparecem nomes como Henry G. Widdowson (1978) na tentativa de perceber as dificuldades que os indivíduos apresentavam em transferir habilidades aprendidas na escola para o mundo real.

$\mathrm{Na}$ contemporaneidade, numa perspectiva mais crítica, aparece Pennycook (2010) afirmando que devemos ver esse objeto como uma parte material da vida sociocultural e não de forma abstrata ou idealizada. Nesse sentido, não se pode deixar de fazer alusão os antigos conceitos filosóficos bakhtinianos, cuja proposta é dar atenção para a língua enquanto fenômeno de interlocução em que os sujeitos são modificados na interação dialógica entre seus enunciados. Seguindo o mesmo raciocínio, Pennycook (2010), parece concordar com a relação de alteridade proposta por Bakhtin (1981), cujo indivíduo modifica-se com a presença do outro. Desta forma, a interação no ambiente comunicativo é responsável pelas construções identitárias desse sujeito que está em constante transformação. Embora Bakhtin (1981) não tenha atribuído dedicação aos aspectos metodológicos de ensino, sabemos que sua posição nos remete a pensar na língua como constituição do sujeito, uma vez que a presença do outro é fundamental para a formação do mesmo e para as construções e reconstruções de sentidos. Assim, se olharmos para os aspectos da língua num paradigma interacionista, veremos que ela também é percebida no âmbito cognitivo, ora atribuída pelos estudos de Vygotsky (1998), o qual remete que a linguagem possui uma relação intrínseca com o pensamento, mas se desenvolve na interação social em que as partes se unem na produção do significado. Por sua vez, a constituição da linguagem pela vertente cognitiva está em interdependência com as relações do ambiente onde os indivíduos são capazes de construir seus conhecimentos. Nesse sentido, a linguagem reafirma sua natureza social, nas relações constituídas pela comunicação. Ela se configura na ação coletiva e não individual.

Na perspectiva da língua como interação pode-se dizer que " [...] o discurso não é individual porque se constrói entre pelo menos dois interlocutores que, por sua vez, são seres sociais” (BARROS, 1996, p. 33). Por sua vez, a língua é um espaço de construção 
de significados do indivíduo, por meio da enunciação e suas relações dialógicas. Ela é também ideológica e permeada por relações de poder. Como ressalta Foucault (1996, apud MENEZES DE SOUZA, 2011, p. 133) “[...] inseparável de nossa genealogia e de nossa produção de linguagem estão as relações de poder que nos regem socialmente de forma assimétrica e desigual”. Ao contrário da perspectiva estruturalista, a língua na interação / no discurso é dinâmica e contempla não só os significados existentes, mas também os que podem ser construídos e ressignificados. Pode-se dizer que os sentidos não são 'dados' independentemente da vontade do sujeito, eles são construídos pelo sujeito inserido no seu entorno social, na cultura e na sociedade. A sua existência se materializa nas práticas sociais, “[...] é um espaço ideológico de construção e atribuição de sentidos" (JORDÃO, 2013a, p. 7). A língua como discurso prevê uma sincronia entre o uso da língua e o contexto.

Nesse sentido, ensinar língua nessa perspectiva propõe-se observar o processo de socialização na construção de significados. Ou seja, é por meio da língua(gem) que os sujeitos podem se posicionar, interpretar e agir criticamente na sociedade na qual estão inseridos. Logo, o processo de ensino de uma língua não pode ser neutro ou desconectado das frentes culturais, políticas e econômicas que circulam na sociedade. Assim, é preciso discutir, por exemplo, porque algumas ideias são aceitas e outras não, numa sociedade complexa e de muitos interesses. Por isso que no que se refere a língua inglesa, os professores parecem considerar que a mudança social ocorre através do ambiente de interação local pensando numa diversidade global. A esse respeito, precisamos buscar formas variadas de aprendizagem que leve em conta a interconectividade, a complexidade de informações que circula no mundo contemporâneo, assim teremos “[...] um deslocamento de aprendizagem, de escolas para o mundo afora" (MENEZES DE SOUZA, 2011, p. 288).

Por sua vez, Pennycook (2007) advoga em prol da desinvenção e reconstituição do conceito de língua já que a língua deve ser vista como construção cultural, inventada histórica e discursivamente.

Para Kumaravadivelu (2006, p. 11), “[...] uma visão verdadeira de língua como discurso deve considerar as operações da língua na interface de significados culturais e ideológicos" "7. Ao analisarmos como as relações de significados são construídos pelos

\footnotetext{
7 [...] a truly discourse-based view of language should have considered the higher order operations of language at the interface of cultural and ideological meanings. (tradução livre das autoras)
} 
indivíduos, percebemos que os enunciados são marcados pelas relações de poder que circulam na sociedade. A língua não é neutra, ela marca a cultura e a identidade de um povo. $\mathrm{O}$ autor citado anteriormente ainda ressalta que a língua “[...] é geralmente refletida nas percepções marcadas ideologicamente e práticas de uso da língua que são moldados e remoldados por forças institucionais dominantes, processos históricos e interesses escusos"8 (KUMARAVADIVELU, 2006, p. 11). Numa perspectiva discursiva, o sujeito é ativo, capaz de "ler, se lendo" (MENEZES DE SOUZA, 2011, p. 296), de exercer a consciência crítica de sempre questionar-se, de examinar-se e ressignificar-se continuamente. Isso significa que o sujeito está em constante reelaboração de sentidos, um ser que se vê e enxerga os outros como construtores de sentidos. Ou seja, o processo de construção de sentido é dinâmico e contínuo, sempre se modificando na construção de novos significados. Desse modo, é primordial que docentes de línguas oportunizem a prática da leitura pelo viés do letramento, tendo em vista que letrar vai além da codificação e decodificação mecânica dos sinais gráficos. O Letramento considera os processos sócio históricos da língua, bem como seu caráter político e ideológico utilizando a língua como instrumento de ação social.

Assim, na sequência, traremos algumas concepções de letramento e veremos como essas perspectivas se relacionam com as concepções de língua(gem) apresentadas anteriormente.

\section{O PAPEL DO LETRAMENTO NO ENSINO DE LÍNGUA INGLESA}

Nesta seção discorreremos sobre dois modelos de letramentos (autônomo e ideológico) propostos por Street (2014), bem como as influências destes no ensino de língua inglesa. Desse modo, esta seção está organizada do seguinte modo: primeiramente faremos uma incursão teórica acerca do termo letramento. Em seguida, discutiremos sobre os modelos de letramento, bem como seus impactos no ensino de línguas estrangeiras.

Por sua vez, é importante esclarecer, já de início, que a concepção de letramento a que nos filiamos teoricamente atrela-se à noção de letramento ideológico, visto que este letramento concebe a língua como prática social (STREET, 2014). Nessa perspectiva, o autor citado anteriormente concebe letramento como plural, político e socialmente

\footnotetext{
${ }^{8}[\ldots]$ is usually reflected in the ideologically grounded perceptions and practices of language use that are shaped and reshaped by institutional forces, historical processes, and vested interests. (tradução livre das autoras)
} 
construído. Acreditamos que a discussão nos moldes que propomos é extremamente importante, tendo em vista que ainda perdura em nossa sociedade um ensino que valoriza os letramentos disseminados no contexto escolar em detrimento dos outros contextos sociais. Segundo Soares (2009, p. 33), há indícios que o termo "letramento" foi usado pela primeira vez, em 1986, por Mary Kato, no livro "No mundo da escrita: uma perspectiva psicolinguística", a qual afirma que:

[...] a função da escola, na área da linguagem, é introduzir a criança no mundo da escrita, tornando-a um cidadão funcionalmente letrado, isto é, um sujeito capaz de fazer uso da linguagem escrita para sua necessidade individual de crescer cognitivamente e atender às várias demandas de uma sociedade que prestigia este tipo de linguagem como um dos instrumentos de comunicação (KATO, 1986, p. 7).

Segundo a autora (1986), a escola é a principal agência de letramento, cuja função é tornar os sujeitos letrados e potencialmente atuantes nos diversos contextos, no qual o uso da leitura e da escrita se fazem presentes, porém esta, a escola, “[...] preocupase não com o letramento, como prática social, mas com apenas um tipo de prática de letramento, qual seja, a alfabetização, o processo de aquisição de códigos (...), processo geralmente concebido em termos de uma competência individual necessária para o sucesso e a promoção na escola.” (KLEIMAN, 1995, p. 20).

Kleiman (1995, p. 18), por sua vez, define “[...] letramento como um conjunto de práticas sociais que usam a escrita, como sistema simbólico e como tecnologia, em contextos específicos”. Sobre essa perspectiva Soares (2002), mostra que letramento não é somente práticas de leitura e escrita, mas está relacionado ao uso e a função dessas práticas no âmbito social. Mais recentemente, Soares (2011, p. 29, grifos da autora), afirma que:

\footnotetext{
O surgimento do termo literacy (cujo significado é o mesmo de alfabetismo), nessa época, representou, certamente, uma mudança histórica nas práticas sociais: novas demandas sociais pelo uso da leitura e da escrita exigiram uma nova palavra para designá-las. Ou seja: uma nova realidade social trouxe a necessidade de uma nova palavra.
}

Desse modo, é importante salientar que o papel do docente de línguas não pode estar condicionado a ensinar regras descontextualizadas de gramática, exercícios de fixação e/ou conversação sem propósito comunicativo, visto que os estudantes precisam de engajamento em suas práticas discursivas, caso contrário, perde-se o propósito de 
qualquer sentido do uso da língua. Todavia, a contemporaneidade incita novos modos semióticos de construção de significados. O professor de língua estrangeira precisa estar atento às possíveis demandas do século XXI, como a diversidade global, a emergência de contextos digitais, o fluxo de informação, etc. Assim em consonância com Jordão (2013a, p. 76), comungamos da ideia de que,

[...] o professor deve ser capaz de perceber esta multiplicidade como positiva, articulando sentidos possíveis ativamente, e ensinar seus alunos a construir sentidos novos a partir das diferentes e variadas possibilidades que se lhe apresentam no mundo, dentro e fora da sala de aula. Assim como seu aluno, o professor aprende constantemente novos procedimentos de construção e negociação de sentidos, bem como suas implicações para a vida pessoal e da sociedade como um todo.

Em outras palavras, as aulas de línguas devem se constituir como espaços de discussão e reflexão, para que os estudantes possam compreender melhor seu papel no mundo e, a partir disso, transformar suas realidades, conscientes das relações de poder que estão indiretamente atuando, seja na tentativa de ocultamento do sujeito ou tentando minimizar sua força nas esferas da sociedade. Por isso que Street (2014), defende o modelo de letramento ideológico, no qual as práticas de letramento são plurais, sociais e culturalmente determinadas, portanto, conforme Kleiman (1995, p.21) "[...] os significados específicos que a escrita assume para um grupo social dependem dos contextos e instituições em que ela foi adquirida". De outro ponto de vista, Street (2014), critica o modelo autônomo de letramento, no qual a escrita é concebida como "objeto", capaz de operar transformações por si só, independente das relações de poder que são orquestradas pelos grupos dominantes que determinam que deve ser incluído ou excluído.

Nestes termos, “[...] fator letramento (...) tende a ser visto como uma credencial para o sucesso nas várias formas de ação na comunidade através da linguagem e, por conseguinte, nas várias formas civilizadas, ou legítimas, de exercício do poder e de controle sobre situações e indivíduos" (SIGNORINI, 1995, pp. 161-162).

Já na posição de Kleiman (1995, p. 21), o modelo autônomo coloca a escrita como parte principal para as demais práticas de letramento, sendo que o único modo de adquiri-lo é através dos processos formais de escolarização. Por outro lado, no modelo ideológico “[...] as práticas de letramento, no plural, são social e culturalmente determinadas, e, como tal, os significados específicos que a escrita assume para um grupo social dependem de contextos e instituições em que ela foi adquirida" (KLEIMAN, 1995, 
p. 21). Esse modelo tem como princípio valorizar e considerar não somente os letramentos ensinados na escola, mas também aqueles que os alunos trazem de seu cotidiano e suas vivências. Nessa direção, defendemos um ensino de línguas pautado no letramento ideológico, no qual a "[...] língua é discurso, espaço de construção de sentidos e representação de sujeitos e do mundo" (JORDÃO, 2013b, p. 73).

\section{O CONTEXTO E A METODOLOGIA DA PESQUISA}

Considerando que a existência do homem no mundo está diretamente ligada a linguagem e a sua forma de expressá-la, acreditamos que o ensino de língua perpassa por uma postura influenciada politicamente, por meio da qual algumas ideologias são reveladas, visto que "[...] politizar o ato de pesquisar e pensar alternativas para a vida social são parte intrínseca dos novos modos de teorizar e fazer LA" (MOITA LOPES, 2006, p. 22-23).

Desta forma, metodologicamente, esta pesquisa se insere na abordagem qualitativa tendo em vista que "[...] a pesquisa qualitativa procura entender, interpretar fenômenos sociais inseridos em um contexto" (BORTONI-RICARDO, 2008, p. 35).

Com o intuito de observar algumas concepções que os professores possuem sobre a língua e leitura, primeiramente foi definida a população que participaria da pesquisa, pois conforme Tuckman (2002, p. 337), “[...] a primeira etapa da amostragem é definir a população". Como as pesquisadoras atuam em cidades diferentes do estado do Paraná, os professores participantes convidados são pertencentes a três localidades: Ponta Grossa, Curitiba e Tomazina. Para aumentar o escopo de atuação resolvemos escolher um professor da escola pública e outro da escola privada de cada localidade. Nosso objetivo não foi contrapor escola pública versus escola privada, mas apenas denotar e refletir quais concepções estão mais presentes nessas instituições sob um tratamento igualitário.

Conforme o questionário, abaixo apresentamos um quadro síntese com o perfil dos participantes da pesquisa.

\begin{tabular}{|c|c|c|c|}
\hline Professor & Sexo & Graduação & $\begin{array}{c}\text { Tempo de } \\
\text { magistério }\end{array}$ \\
\hline P1 & F & Letras/inglês & 30 anos \\
\hline P2 & M & Letras/inglês & 22 anos \\
\hline P3 & F & Letras/inglês & 28 anos \\
\hline P4 & F & Letras/inglês & 16 anos \\
\hline P5 & M & Letras/inglês & 8 anos \\
\hline P6 & F & Letras/inglês & 4 anos \\
\hline
\end{tabular}

Quadro 1: Características dos professores respondentes.

Fonte: Elaborado pelas autoras. 
O primeiro contato foi realizado pessoalmente, com a finalidade de formalizar o convite para a participação do estudo. Expusemos e explicamos os objetivos da pesquisa e apresentamos o Termo de Consentimento Livre e Esclarecido. Na ocasião também foi entregue o instrumento por meio do qual os dados foram gerados.

Posteriormente, com o objetivo proposto de refletir a respeito da concepção de língua e leitura dos professores, organizamos como seria o instrumento de geração dos dados. No que se refere à concepção de língua(gem) o professor poderia assinalar dentre quatro opções a seguinte pergunta: "Que concepção está condizente com a sua ideia do que vem a ser ensinar / aprender língua e língua(gem)?”. Procuramos nas opções buscar citações de autores (JORDÃO, 2013b; MENEGASSI, 2013; MENEZES DE SOUZA, 2011; PARANÁ, 2008) que transmitissem a ideia de língua(gem) como sistema, interação e discurso. Na sequência, elencamos uma pergunta aberta: "Que concepção de língua estrangeira embasa sua prática?"

Para dar suporte ao objeto de estudo, também oferecemos três definições de leituras proposta por autores (MENEZES DE SOUZA, 2011; PARANÁ, 2008, LEFFA, 1988), dentre as quais os docentes deveriam escolher a que fosse mais condizente com sua prática de leitura empregada em sala de aula. Assim, como na questão anterior, apresentamos em seguida uma pergunta aberta: "Como você trabalha a leitura nas aulas de língua estrangeira?"

A partir das respostas a esses questionários semiestruturados e estruturados foram extraídos eixos para análise. Procuramos com isso obter subsídios para a compreensão da concepção de língua(gem) dos docentes participantes, bem como estabelecer ligações entre os relatos dos docentes e suas práticas e concepções assinaladas.

$\mathrm{Na}$ sequência apresentamos a análise dos dados organizados pelos eixos temáticos, propostos neste trabalho, seguido das considerações finais.

\section{CONCEPÇÃO DA LÍNGUA(GEM) PELOS DOCENTES}

Em relação ao primeiro tópico sobre a concepção de língua, observamos que todos os participantes assinalaram que sua prática docente tem como parâmetro a língua como discurso. Nessa concepção, a língua é vista pelo modelo ideológico de letramento, por meio do qual os sentidos são (re)construídos entre os interlocutores em práticas discursivas. Ao nosso ver, essa é uma concepção pós-estruturalista, que retrata a língua 
como discurso. No entanto, constatamos que alguns se contradisseram quando foram solicitados a responderem a seguinte pergunta: “Que concepção de língua estrangeira embasa sua prática?" Vejamos alguns trechos das declarações.

\begin{tabular}{|c|l|}
\hline Participantes & \multicolumn{1}{|c|}{ Concepção de língua que embasa a prática dos docentes } \\
\hline$P 1$ & $\begin{array}{l}\text { [...] baseada na corrente sociológica e nas teorias de Bakhtin, (...) propõe-se que a } \\
\text { aula de Língua Estrangeira Moderna constitua um espaço para que o aluno reconheça } \\
\text { e compreenda a diversidade linguística e cultural, de modo que se envolva } \\
\text { discursivamente e perceba construção de significados em relação ao mundo em que } \\
\text { vive. }\end{array}$ \\
\hline [...]a normatização da língua é lapidada ao longo do processo. \\
\hline$P 3$ & $\begin{array}{l}\text { [...] língua tem variedades, porém algumas são mais valorizadas (...). É por meio da } \\
\text { língua que interagimos com o mundo. Discutimos a importância de nos } \\
\text { posicionarmos, produzir sentidos. }\end{array}$ \\
\hline P4 & $\begin{array}{l}\text { [...] contexto ensino/aprendizagem, na contextualização do tripé (língua, cultura, } \\
\text { identidade) como eixo da constante transformação. }\end{array}$ \\
\hline $\begin{array}{l}\text { O Ensino de língua deve materializar o sentido de construção de } \\
\text { ensinolaprendizagem, por meio de situações diretamente relacionadas as próprias } \\
\text { experiências, e não apenas valores artificiais. O contexto favorece construção de } \\
\text { sentidos (...) impulsiona o apropriar-se do conhecimento }\end{array}$ \\
\hline $\begin{array}{l}\text { [...] todos temos capacidade para aprender línguas estrangeiras(...) o contato cedo } \\
\text { colabora (...), portanto utilizo a língua inglesa em sala de aula sempre e os instigo a } \\
\text { utilizá-la também. }\end{array}$ \\
\hline P6
\end{tabular}

Quadro 2: Concepção de língua(gem).

Fonte: Elaborado pelas autoras.

Analisando os trechos podemos inferir que as respostas de $P 1$ e $P 3$ estão coerentes com a alternativa assinalada sobre concepção de língua(gem). Tanto $P 1$ quanto P3 reconhecem que língua possui variedades, portanto são plurais, que não há língua "pura", ou seja, a mescla é inerente a todas as línguas. Ao expor que por meio da língua construímos sentidos e significados em relação ao mundo em que se vive, podemos entender que esses docentes têm procurado ensinar língua como prática social (JORDÃO, 2013a). P3 ao dizer que algumas variedades são mais valorizadas, denota que a língua possui um valor simbólico (BORDIEU, 2005), por meio do qual os falantes são excluídos ou incluídos, sendo que estes fatores são sempre ideológicos e políticos.

Embora $P 4$ e $P 5$ não tenham dito explicitamente qual concepção de língua(gem) embasa suas práticas, suas respostas sugerem que há reflexões importantes que devem ser consideradas no ensino de línguas. Por exemplo, quando $P 4$ diz que o ensino de língua deve levar em conta a ligação intrínseca entre língua, cultura e identidade, entendemos que a professora amplia a concepção, dando a entender que o ato de ensinar língua(gem), não se restringe a aspectos gráficos, pronúncia e estruturas gramaticais. 
Concordamos com P4 quando diz que o ensino de língua deve ser atrelado a cultura e identidade, pois embora uma língua não seja determinante, ela é uma representação importante da identidade e da cultura de um povo, tendo em vista que ambas são veiculadas pela ordem do discurso, ou seja, é por meio da língua que tanto a identidade quanto a cultura são veiculadas e modificadas, por isso estão sempre em transformação.

P5 por sua vez, afirma que o ensino de línguas deve ocorrer por meio de situações diretamente relacionadas as próprias experiências, e não apenas valores artificiais. $O$ contexto favorece construção de sentidos (...) impulsiona o apropriar-se do conhecimento. Neste trecho, observamos que embora o docente não tenha conseguido formular completamente a concepção que embasa sua prática (considerando que não é algo fácil e tão pouco simples), no nosso ponto de vista entendemos que ele percebe língua como dinâmica, isto é, que os sentidos são construídos entre os interlocutores a partir dos contextos.

No entanto, pode-se dizer que a resposta de $P 2$ “[...] a normatização da língua é lapidada ao longo do processo", retrata ainda a ideia de alguns docentes do Brasil, do que seja ensinar e/ou aprender língua, visto que somos frutos desse ensino conteudista, no qual este estava relacionado ao ensino e aprendizagem de normas e estruturas. Havia um ideal de língua a ser alcançado, o qual incluía pronúncia próxima aos nativos, o ensino do inglês "americano" ou "britânico". A respeito disso, há uma grande discussão crítica sobre esse aspecto, principalmente no que se refere a posição imperialista sobre a língua hegemônica desses países, conforme apresentado na pesquisa de Jenkins (2013) sobre os estudos de língua franca, a qual menciona as dificuldades que falantes estrangeiros enfrentam pela busca do idealismo linguístico, que é bastante valorizado e disseminado principalmente por escolas de idiomas que, ensinam língua como um sistema restrito pelas condições internas referentes aos aspectos formais da língua.

Em relação a $P 6$ percebemos que seu posicionamento se deslocou para a perspectiva cognitiva de que há estágios propícios para a aquisição da língua, não se colocando de forma abrangente sobre sua concepção voltada ao ensino. Em seguida, analisaremos as práticas de leitura e se elas correlacionam com as posturas pedagógicas. 
Nesta seção analisamos a concepção de prática de leitura que norteia o trabalho dos professores participantes da pesquisa. Para isso disponibilizamos um questionário estruturado e também de uma pergunta aberta com algumas concepções de leitura. As concepções de leitura disponibilizadas foram extraídas dos seguintes autores: (MENEZES DE SOUZA, 2011; LEFFA, 1988) e do Currículo Básico para a Escola Pública do Estado do Paraná (PARANÁ, 2008). Conforme os trechos assinalados pelos docentes, podemos inferir que estes parecem concordar com o que propõe as Diretrizes Curriculares da educação Básica do Paraná (DCEs) a respeito de como deve ocorrer a leitura.

O trecho mais assinalado pelos professores retrata que a leitura deve ser compreendida:

[...] como um ato dialógico, interlocutivo, que envolve demandas sociais, históricas, políticas, econômicas, pedagógicas e ideológicas de determinado momento. Ao ler, o indivíduo busca as suas experiências, os seus conhecimentos prévios, a sua formação familiar, religiosa, cultural, enfim, as várias vozes que o constituem. (PARANÁ, 2008, p. 56).

Apenas um educador assinalou a definição de leitura como ato reflexivo. Logo,

[...] o processo de ler criticamente envolve aprender a escutar não apenas o texto e as palavras que o leitor estiver lendo, mas também - e talvez mais crucialmente no mundo de conflitos e diferenças de hoje - aprender a escutar as próprias leituras de textos e palavras. Isso quer dizer que ao mesmo tempo em que se aprender a escutar, é preciso aprender a se ouvir escutando. (MENEZES SOUZA, 2011, p. 131- grifos do autor).

Embora tenha assinalado a concepção acima, isto não significa que o docente possua uma postura totalmente crítica em relação a leitura, tendo em vista que a leitura crítica extrapola o mundo de textos e palavras. A leitura crítica pressupõe também que fazemos com as leituras na busca da transformação da sociedade e no questionamento de parâmetros e dogmas que são tidos como absolutos e verdadeiros. Portanto, ler criticamente na perspectiva de Menezes Souza, implica em preparar o outro, para o complexo, para a diversidade e para o conflito constante. Ou seja, é "[...] preparar aprendizes para confrontos com diferenças de toda espécie se torna um objetivo pedagógico atual e premente [...]" (MENEZES SOUZA, 2011, p. 2). Assim, considerar que o professor adota uma postura crítica de leitura com base apenas no trecho assinalado seria impossível. 
Sob outra perspectiva, conforme os trechos analisados abaixo observamos que os professores, em geral, reconhecem que a leitura é um processo ativo na construção dos significados e que envolve um processo contínuo de amadurecimento intelectual. Além disso, percebemos que os professores estão conscientes que a leitura reflexiva e crítica é o caminho para formarmos cidadãos mais politizados e conscientes, já que por muito tempo, o ato de ler foi associado a decodificação, ou ao uso do texto como pretexto para atividades sem engajamento social e atrelado a análise gramatical.

Nessa direção, além do professor poder escolher a prática de leitura condizentes com suas perspectivas solicitamos que eles dissertassem sobre o modo que trabalhavam a leitura nas aulas de línguas estrangeiras. Nosso intuito com esse questionamento foi oportunizar uma reflexão para que os docentes de modo geral pudessem discorrer sobre sua prática. Vejamos abaixo alguns excertos das respostas dos professores.

\begin{tabular}{|c|c|}
\hline Participantes & Prática de leitura nas aulas de língua estrangeira \\
\hline$P 1$ & $\begin{array}{l}\text { Utilizando gêneros textuais diversos trazidos pelo livro didático “Way to go" (...) } \\
\text { estabelecendo relação com o conhecimento prévio trazido pelo aluno. Por meio de } \\
\text { textos verbais e não- verbais fazemos a leitura tentando fazer uma reflexão crítica } \\
\text { para então fazermos a leitura e praticarmos a pronúncia. }\end{array}$ \\
\hline$P 2$ & $\begin{array}{l}\text { Do micro, pronúncia e contexto de palavras, ao macro, passando da palavra para uma } \\
\text { frase, depois parágrafo e depois todo o texto. }\end{array}$ \\
\hline$P 3$ & $\begin{array}{l}\text { As leituras em minhas aulas são trabalhadas com técnicas de skimming e scanning a } \\
\text { partir do texto (...) o conhecimento prévio que eles (o aluno) possuem (...) os cognatos } \\
\text { também auxiliam muito na interpretação e compreensão dos textos nas leituras. }\end{array}$ \\
\hline$P 4$ & $\begin{array}{l}\text { [...] trabalho com a leitura não é algo fácil e acabado, busco estratégias com leitura } \\
\text { de informação com prioridade para textos autênticos que remeta o aluno a reflexão } \\
\text { sobre acontecimento do seu dia a dia, o grau de dificuldade avança gradativamente } \\
\text { [...]. }\end{array}$ \\
\hline$P 5$ & $\begin{array}{l}\text { [...] A leitura é sempre um ato dialógico (...) todo indivíduo tem papel ativo no } \\
\text { processo de leitura (...) toda leitura deve instaurar um processo de troca, uma ação } \\
\text { partilhada (...) deve-se enfatizar que todo texto é estruturado a partir de um valor } \\
\text { socialmente construído. }\end{array}$ \\
\hline P6 & $\begin{array}{l}\text { [...] os estudantes leem o texto que utilizamos em sala em voz alta. (...) passamos } \\
\text { alguns minutos lendo o texto juntos e eles respondem as perguntas relacionadas ao } \\
\text { texto em casa. Procuro sempre por textos curtos, de determinados gêneros, mas que } \\
\text { seja de um assunto atual e que eles se interessem. }\end{array}$ \\
\hline
\end{tabular}

Quadro 3: Prática de leitura nas aulas de língua estrangeira.

Fonte: Elaborado pelas autoras.

Examinando a resposta $P 1$, pode se dizer que, embora ele preze pelo ensino a partir de gêneros textuais variados, sua prática ainda está bastante pautada no livro didático. Há preocupação, por parte deste professor, em oportunizar aos educandos uma leitura crítica, antes de pensar em questões formais da língua. No entanto, $P 2$ ao referirse "Do micro, pronúncia e contexto de palavras, ao macro, passando da palavra para uma frase, depois parágrafo e depois todo o texto", nos pareceu uma prática de leitura 
descontextualizada, sem considerar o processo interativo e dialógico descrito por ele anteriormente. Nesse sentido, percebemos que embora haja consciência em relação às concepções críticas de leitura, quando o mesmo relata o cenário de suas práticas, percebese que há forte tendência estruturalista de ensino implicitamente. Por sua vez, as respostas dos docentes P3 e P6 levam-nos a entender que a leitura pode se dar de modo técnico, cujo objetivo é decifrar as palavras. Entretanto, nossa análise não deve ser vista como uma crítica negativa, considerando que decifrar sinais gráficos também faz parte do processo de leitura. No entanto, a leitura não se deve restringir a codificação e decodificação, conforme afirmamos na seção - concepção de língua(gem). Assim, advogamos em prol de ensino de leitura que vá além do que está escrito, que perceba que os textos são produtos sociais e históricos, portanto, são escritos com objetivos específicos, para atingir os sujeitos que fazem parte desse mundo letrado.

Em seguida, $P 4$ expressa consciência do quão complexo é o processo de ensinar a leitura. A preferência por textos autênticos também demonstra que o trabalho com a leitura extrapola os gêneros textuais dos textos em questão, trazido pelos livros didáticos, que o aluno precisa usar estratégias para suprir suas dificuldades.

Infelizmente, $P 5$ não conseguiu descrever a prática empregada em suas aulas de língua estrangeira. Ele apenas repete a sua concepção de leitura assinalada no questionário anterior, não oportunizando nossa análise.

Além das perguntas relacionadas ao tema de língua e leitura, também aplicamos um questionário (trechos 1 - 10) que seguiu a estrutura da "escala de Likert" (TUCKMAN, 2002, p. 279). O professor deveria marcar com um (X) em uma das alternativas concorda, discorda ou sem opinião na afirmação ${ }^{9}$ que melhor respondesse a seguinte questão: “Que práticas são mais utilizadas na sua sala de aula? ”. Na sequência, apresentamos um gráfico e posterior análise de três afirmações relacionadas à prática pedagógica dos docentes.

\footnotetext{
${ }^{9}$ As afirmações foram retiradas de depoimentos de professores e autores como Mattos (2011), Marzari e Badke (2013), Motta (2008), Norton e Toohey (2011).
} 


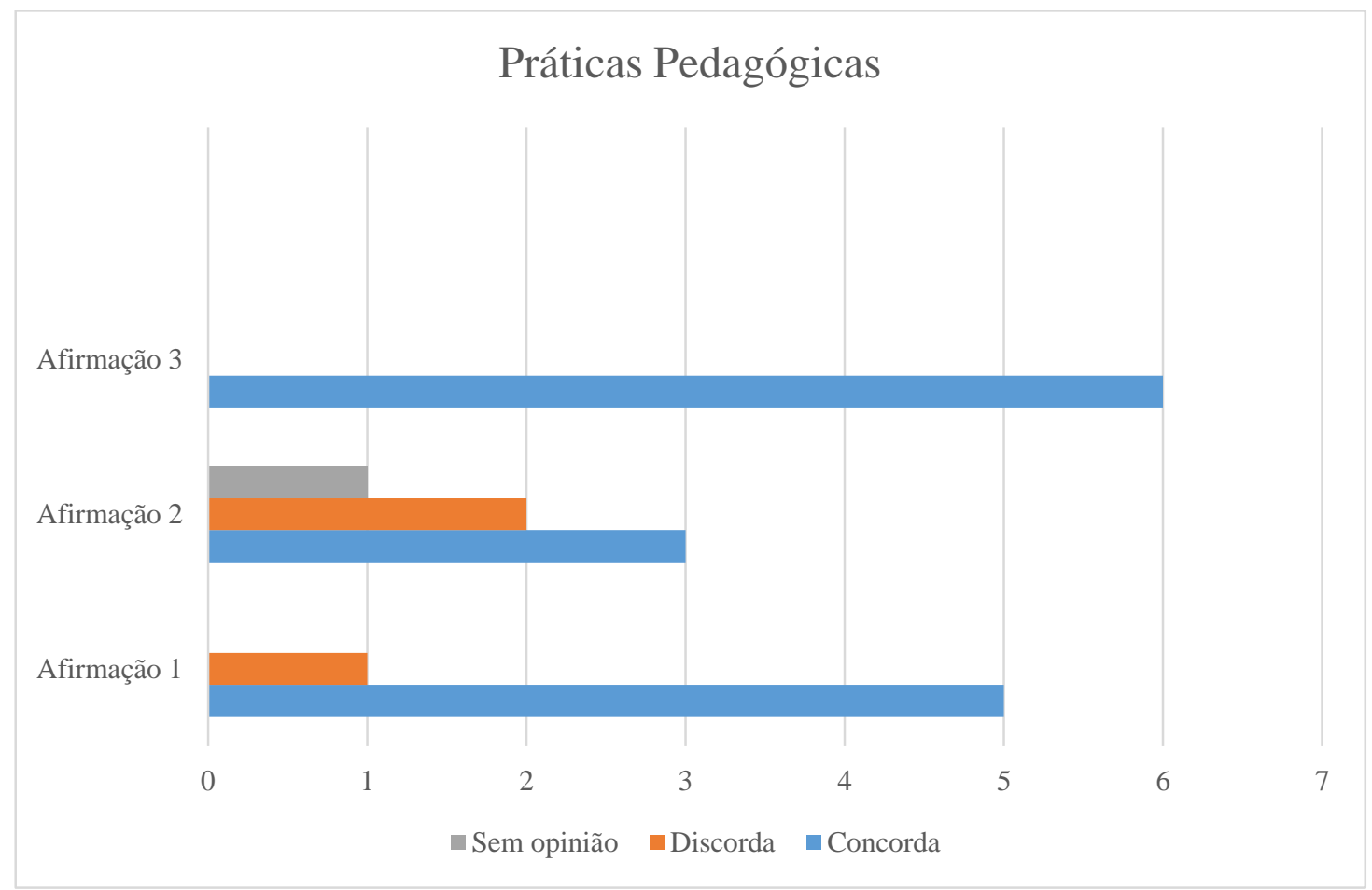

Gráfico 1: Gráfico elaborado a partir de três afirmações mais citadas sobre a prática pedagógicas assinaladas pelos professores.

Fonte: Elaborado pelas autoras

\section{LEGENDA}

\begin{tabular}{|c|c|}
\hline Afirmação 1 & $\begin{array}{l}\text { "[...] no ensino de língua estrangeira (LE), quando se ensinam primeiro os } \\
\text { verbos regulares, considerados mais simples e fáceis, e depois os verbos } \\
\text { irregulares, considerados mais complexos, ou quando se ensina o sistema } \\
\text { modo-temporal dos verbos em inglês, começando-se pelo tempo verbal } \\
\text { tradicionalmente considerado mais simples - o 'Present Simple' - até } \\
\text { chegar aos tempos mais complexos, como o 'Present Perfect' e o 'Past } \\
\text { Perfect". (MATTOS, 2011, p. 35) }\end{array}$ \\
\hline Afirmação 2 & $\begin{array}{l}\text { Eu sigo o livro didático, sigo as perguntas e respostas propostas no material. } \\
\text { "[...] as atividades variam desde exercícios de gramática, ditados, pesquisas, } \\
\text { escuta e compreensão de letras de música e leituras". (MARZARI, G. Q.; } \\
\text { BADKE, M. R., 2013, p. 14) }\end{array}$ \\
\hline Afirmação 3 & $\begin{array}{l}\text { "[...] práticas pedagógicas tem o potencial de transformar estudantes de } \\
\text { língua, oferecendo o poder do uso da língua dentro e fora da escola }{ }^{10} \\
\text { (NORTON; TOOHEY, 2011, p. 417), negociando significados que serão } \\
\text { compartilhados em diferentes contextos sociais. É com a inserção do aluno } \\
\text { com a linguagem que o mesmo irá ter acesso os meios sociais. }\end{array}$ \\
\hline
\end{tabular}

Os resultados sugerem que, embora os professores acreditem no poder transformador das práticas pedagógicas no contexto escolar e também exterior a ele, observamos pela afirmação de número 3, que ainda há professores que se contradizem

\footnotetext{
${ }^{10}[\ldots]$ pedagogical practices have the potential to be transformative in offering language learners more powerful positions than those they may occupy either inside or outside the classroom. (Tradução das autoras)
} 
quando descrevem suas atitudes práticas, o que remete pensarmos que a prática em sala de aula enfrenta problemas, necessitando, portanto, de direcionamentos mais críticos sobre práticas de ensino. Por outro lado, isto também nos leva a refletir que nem sempre a teoria da conta da prática, por isso, como educadores, devemos ter em mente que não há uma única teoria e pratica a seguir, os sujeitos são diferentes no processo de aprender, portanto exigem teorias e práticas diversas.

$\mathrm{Na}$ afirmação 1, cinco professores assinalaram que o ensino de língua inglesa deve partir de estruturas mais simples para mais complexas. Apenas a participante $P 1$ discordou dessa perspectiva. As opiniões também foram distintas na afirmação 2, a qual discorria sobre o uso do livro didático como material de apoio mais influente no processo de aprendizagem. Sobre isso, três professores assinalaram a opção que se referia ao uso fiel ao livro didático, utilizando as atividades propostas no material.

Em contrapartida, com base nas respostas dos participantes, em relação a afirmação 3, podemos inferir que todos concordam que o ensino de línguas deve oportunizar práticas negociadas de sentidos para formar sujeitos que possam inserir e atuar em diversos contextos sociais, já que os seis participantes demonstraram possuir a mesma opinião em relação a esta afirmação. Para a afirmação 2, tivemos três participantes concordando com o uso mais centrado no material didático e a visão mais estruturalista de ensino. Isso pode decorrer da própria formação do professor ou por questões subjetivas que permeiam as práticas de ensino. Por último, cinco dos participantes concordaram com a afirmação 1 que também remete a uma posição tradicional de ensino, já que pressupõe um ensino calcado na fragmentação dos conteúdos e na abordagem condicionada ao nível de proficiência.

Assim, após as análises aqui apresentadas, na sequência apresentamos algumas considerações acerca da pesquisa proposta. Salientamos, que conforme a perspectiva discursiva de língua(gem), por nós, adotadas neste trabalho as análises apresentadas não devem ser vistas como únicas ou definitivas, mas sim como o processo, que poderá sempre ser retomado e discutido.

\section{ALGUMAS CONSIDERAÇÕES FINAIS}

A partir das reflexões aqui apresentadas percebemos que o caminho para um ensino de língua(gem) crítica que preze pelo letramento crítico e ideológico dos sujeitos ainda é algo a ser pensado pelos educadores de forma consciente. Reconhecemos que as 
concepções manifestadas pelos professores, talvez, sejam resultados de direcionamentos dos documentos oficiais, tais como Parâmetros Curriculares Nacionais - PCN (BRASIL, 1998) e das Diretrizes Curriculares da Educação Básica - DCE (PARANÁ, 2008), que preconizam que o Ensino de Língua Estrangeira deve ser pautado numa concepção de língua como prática social fundamentada na abordagem comunicativa.

No entanto, a análise também evidencia que há muitas contradições entre alguns participantes em relação a concepção de língua(gem) e prática pedagógica. Nesse sentido, percebemos que as práticas dos docentes estão mais calcadas no modelo estruturalista, enquanto que a concepção de língua(gem) se orienta num viés mais sócio discursivo. Ainda assim, vemos essas contradições como inerentes ao processo de formação continuada, pois como bem sabemos conceituar língua(gem), na perspectiva proposta, é algo extremamente complexo e conflituoso, visto que muitos educadores foram formados dentro do paradigma estruturalista. É importante salientar que a pesquisa aqui apresentada não teve objetivo de apontar o que é certo ou errado ou ainda desqualificar o trabalho dos professores participantes que prontamente atenderam a nossa solicitação, mas sim de propor uma discussão sobre o ensino de língua para que juntos possamos melhorar cada vez mais o ensino e formamos cidadãos mais conscientes que saibam usar a língua em benefício próprio.

Sendo assim, conforme já afirmado anteriormente, não podemos esquecer que a prática desses docentes é resultado de suas formações, portanto não cabe aferir a eles toda a responsabilidade, sendo que muitos deles são produtos de uma formação conteudista e estruturalista. Por isso, defendemos que as universidades estreitem os laços com a educação básica, oferecendo por meio das Secretarias municipais e estaduais cursos de formação continuada que oportunizem aos educadores momentos de reflexões e leituras sobre concepções e metodologias mais críticas, para que estes possam ressignificar continuamente suas práxis de modo a atender essa sociedade plurilinguística.

\section{REFERÊNCIAS BIBLIOGRÁFICAS}

BAKHTIN, M. Marxismo e Filosofia da Linguagem: Problemas fundamentais do método sociológico da linguagem. Trad. Michel Lahud et al. 12 ${ }^{a}$ Ed. São Paulo : Hucitec, 2006.

Le discours dans la vie et dans la poésie. In: TODOROV, T. Mikhail Bakhtine: le principe dialogique. Paris: Éditions du Seuil, 1981. 
BAKHTIN, M.; VOLOCHINOV, M. Marxismo e filosofia da linguagem. 6. ed. São Paulo: Hucitec, 1992.

BARROS, D. L. P. Contribuições de Bakhtin às teorias do texto e do discurso. In: FARACO, C. A.; TEZZA, C.; CASTRO, G. (Orgs.) Diálogos com Bakhtin. Curitiba: Editora da Universidade Federal do Paraná, 1996. pp. 21-42.

BORDIEU, P.A economia das trocas simbólicas. São Paulo: Perspectiva, 2005.

BORGES, E. F.V. Um modelo caótico de desenvolvimento reflexivo da profissionalidade de professores de línguas. In: ReVEL, v. 14, n. 27, pp.364-388, 2016. Disponível em: <http://www.revel.inf.br/files/860c6939db9da1692c64f5c283a9c376.pdf> Acesso em 10 de outubro de 2016.

BORTONI-RICARDO, S. M. O professor pesquisador: introdução à pesquisa qualitativa. São Paulo: Parábola Editorial, 2008.

BLOOMFIELD, L. A set of postulates for the science of language. Language: Linguistic Society of America, v. 2, n. 3, 1926. pp. 128-138. Disponível em: $<$ http://emilkirkegaard.dk/en/wp-content/uploads/A-Set-of-Postulates-for-the-Scienceof-Language.pdf > Acesso em 19 de outubro 2016.

BRASIL. Parâmetros Curriculares Nacionais. Área de linguagens e códigos e suas tecnologias. O conhecimento em Língua Estrangeira Moderna. Brasília: MEC, 1998.

BRONCKART, J. P. Atividade de Linguagem, discurso e desenvolvimento humano. Campinas, SP: Mercado das Letras, 2006.

DUARTE, J. G.; MILANI, S. E.; PINHO, M. J. As contribuições dos ensinamentos de Leonard Bloomfield para a Linguística. In: Cadernos do Círculo Fluminense de Estudos Filológicos e Linguísticos. v. XVII, n. 9. Rio de Janeiro: CiFEFiL, 2013.

JENKINS, J. English as a Lingua Franca in the international university: the politics of academic English language policy. Abingdon, GB: Routledge, 2013.

JORDÃO, C. M. Abordagem comunicativa, pedagogia crítica e letramento crítico farinhas do mesmo saco? In: ROCHA, C. H.; MACIEL, R. F. (Orgs.) Língua Estrangeira e Formação Cidadã: por entre discursos e práticas. (Orgs.). Coleção: Novas perspectivas em Linguística Aplicada. Vol. 33. Campinas, SP: Pontes Editores, 2013a. pp.69-90.

In: SILVA, K. A.; ARAGÃO, R. C. (Orgs.). Conversas com formadores de professores de línguas: avanços e desafios. Campinas, SP: Pontes Editores, 2013b.

KATO, M. No mundo da escrita. São Paulo. Ática, 1986.

KLEIMAN, A. B. Modelos de letramentos e as práticas de alfabetização na escola. In: Os significados do letramento: uma nova perspectiva sobre a prática social da escrita. Campinas, SP: Mercado das Letras, 1995. pp.15-61. 
KUMARAVADIVELU, B. Understanding Language Teaching: from method to postmethod. New York: Routledge, 2006.

LARSEN FREEMAN, D. Techniques and Principles in Language Teaching. In: CAMPBELL, R. N.; RUTHERFORD, W. E. Teaching Techniques in English as a Second Language. New York: Oxford, 2000. pp.1-189.

LEFFA, V. J. Metodologia do ensino de línguas. In: BOHN. H. I.; VANDRESEN, P. Tópicos em linguística aplicada: $\mathrm{O}$ ensino de línguas estrangeiras. Florianópolis: Ed. Da UFSC. 1988. pp. 211-236.

MAKONI, S.; PENNYCOOK, A. (Ed.) Disinventing and reconstituting languages. Clevedon: Multilingual Matters, 2007.

MARZARI, G. Q.; BADKE, M. R. Ensino e aprendizagem de língua inglesa em escolas públicas de Santa Maria/ RS. Pesquisas em Discurso Pedagógico, v.1. n.1,pp.1-21, 2013.

MATTOS, A. M. A. Novos letramentos, ensino de língua estrangeira e o papel da escola pública no século XXI. In: JORDÃO, C. M. (Org.) Letramentos e Multiletramentos no ensino de línguas e literaturas. Revista X, v. 1, n.1, pp.33-47, 2011.

MENEGASSI, J. R. In: SILVA, K. A.; ARAGÃO, R. C. (Orgs.). Conversas com formadores de professores de línguas: avanços e desafios. Campinas, SP: Pontes Editores, 2013.

MENEZES DE SOUZA, L. M. T. O Professor de Inglês e os Letramentos no século XXI: métodos ou ética? In: JORDÃO, C.M.; MARTINEZ, J.Z; HALU, R.C. (Orgs.). Formação (Des)formatada: práticas com professores de língua inglesa. São Paulo: Pontes, 2011. pp. 279-303.

Para uma redefinição de Letramento Crítico: conflito e produção de Significação. In: MACIEL, R. F.; ARAUJO, V. A, (Orgs.). Formação de professores de línguas: ampliando perspectivas. Jundiaí: Paco editorial, 2011.

MOITA LOPES, L. P. Uma linguística aplicada mestiça e ideológica: interrogando o campo como linguista aplicado. In: MOITA LOPES, L.P. (org.). Por uma linguística aplicada indisciplinar. 2 ed. São Paulo: Parábola Editorial, 2006.pp.13-44.

MOTTA, A. P. F. O letramento crítico no ensino de língua inglesa sob a perspectiva docente. Programa de Desenvolvimento Educacional, Londrina, 2008. Disponível em: $<$ http://www.diaadiaeducacao.pr.gov.br/portals/pde/arquivos/379-4.pdf> Acesso em 08/07/16.

NORTON, B.; TOOHEY, K. Identity, language learning, and social change. Language Teaching, v.44, n.4, pp 412-446, 2011.

PARANÁ. Secretaria de Estado de Educação. Diretrizes Curriculares da Educação Básica, Língua Estrangeira Moderna, Curitiba, 2008. Disponível em: 
<http://www.educadores.diaadia.pr.gov.br/arquivos/File/diretrizes/dce_lem.pdf > Acesso em 8 de julho de 2016.

Secretaria de Estado de Educação. Diretrizes Curriculares da Educação

Básica - Língua Portuguesa. Paraná, 2008. Disponível em <http://www.educadores.diaadia.pr.gov.br/arquivos/File/diretrizes/dce_port.pdf> Acesso em 8 de julho de 2016.

PENNYCOOK, A. The Myth of English as an International Language. In: PENNYCOOK \& MAKONI, S. (Ed.) Desinventing and Reconstituting Languages. Clevendon: Multilingual Matters, 2007, pp.90-115.

Language as a local practice. London: Routledge, 2010.

POSSENTI, S. Por que (não) ensinar gramática na escola. Campinas, SP: ALB: Mercado das Letras, 1997.

SAUSSURE, F. Curso de linguística geral. Organização de Charles Bally e Albert Sechehaye com a colaboração de Albert Riedlinger. Tradução de Antônio Chelini, José Paulo Paes e Izidoro Blikstein. 27ª ed. São Paulo: Cultrix, 2006.

SIGNORINI, I. Letramento e (in) flexibilidade comunicativa. In: KLEIMAN, A. B. Os significados do letramento: uma nova perspectiva sobre a prática social da escrita. Campinas, SP: Mercado de Letras, 1995. Pp.161-200.

SILVA, K. A.; ARAGÃO, R. C. (Orgs.) Conversas com formadores de professores de línguas: avanços e desafios. Campinas: Pontes Editores, 2013.

SOARES, M. Letramento: um tema em três gêneros. 3 ed. Belo Horizonte: Autêntica, 2009

Alfabetização e letramento. 6 ed. São Paulo: Contexto, 2011.

STREET, B. V. Letramentos sociais: abordagens críticas do letramento no desenvolvimento, na etnografia e na educação. Tradução: Marcos Bagno. São Paulo: Parábola Editorial, 2014.

TRAVAGLIA, L. C. Gramática e interação: uma proposta para o ensino de gramática no $1^{\circ}$ e $2^{\circ}$ graus. São Paulo: Cortez, 1996.

TUCKMAN, B. W. Manual de Investigação em Educação: como conceber e realizar o processo de investigação em Educação. 2. ed. Lisboa: Fundação Calouste Gulbenkian, 2002.

VYGOTSKY, L. S. Pensamento e Linguagem. Rio de Janeiro: Martins Fontes, 1998

WIDDOWSON, H. G. Teaching Language as Communication. London: Oxford, 1978. 